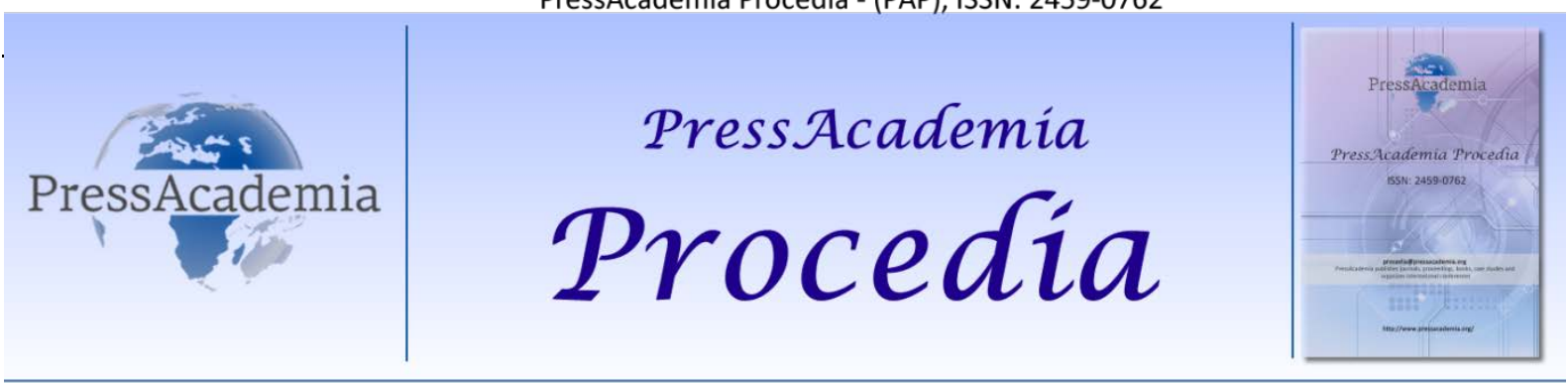

Global Business Research Congress (GBRC), May 26-27, 2016, Istanbul, Turkey.

\title{
PERFORMANCE OF NATIONAL INNOVATION SYSTEMS DURING THE GLOBAL CRISIS: A CROSS-COUNTRY ANALYSIS
}

\section{DOI: 10.17261/Pressacademia.2016118626}

\author{
Emine Nur Gunay Ozkan, Gozde Nur Kazazoglu \\ ${ }^{1}$ Senior Economic Advisor to Prime Ministry, enurgunay@gmail.com \\ ${ }^{2}$ Economic Advisor in Prime Ministry, gozde.kazazoglu@gmail.com
}

\begin{abstract}
The Global Financial Crisis of 2007-2009, followed by the Euro Crisis, changed the world economic and social balances. By turning upside down the letter-perfect and internalized global economic and social judgments and expectations, the Global Financial Crisis gave birth to a new world order and to a 'new normal'. Since the internal dynamics of the firms, sectors, countries and regions differ highly, the effect of the global crisis to firms, sectors, countries and regions in terms of intensity of the shock and the recovery process was also uneven. This new normal, together with the technological development, increased the importance of the innovation and efficient use of scarce resources to avoid deadlock in the inclusive and sustainable growth. Thus, the aim of this study is to focus on the innovation efficiency of the countries to see the effect of the global crisis on the capabilities of the countries. In this study, two alternative models with two different approaches of Data Envelopment Analysis (DEA) under two different specifications (input-oriented and output-oriented) are utilized to trace innovation performance across 56 countries during the global crisis from 2007 to 2012 . The empirical evidence reveals that the negative effects of 2008 crisis are reflected on innovation efficiencies of countries in 2008 in the base model and 2009 in the lag model. In addition, grouping countries according to their GDP and GDP per capita and implementing two different models show that there could be difference in the innovation efficiency results since the DEA model shows the innovation efficiency in comparison with the other countries' efficiency. Lastly, with the data it is observed that higher GDP or higher GDP per capita do not lead to high innovation efficiency.
\end{abstract}

Keywords: innovation, efficiency, national innovation systems

JEL Codes: O30, F60

\section{INTRODUCTION}

After the recent financial turmoil, the world, with an average economic growth of $2.08 \%$ between 2007 and 2012 , takes the notion of innovation as the basis of the growth and development. The slowdown in the growth and mass production caused by the crisis needed to be stimulated by research and development, which, it was hoped, would lead to innovation and sustainable growth.

In order to increase productivity, developed countries started to give more importance to a knowledge-based economy and to innovation, while developing countries started to aim at deepening their ICT infrastructure and skills and increasing their research and development expenditures to increase foreign direct investment inflow and to maintain the high growth rates which they had achieved during the crisis period. In that context, this study underlines the role and the definition of a knowledge-based economy, its relationship to innovation and national innovation efficiency by analyzing the inputs used and outputs created after the 2007 financial crisis. 
With the rise of the use of information and communication technologies (ICT) and with the 2009 world financial crisis, rather than orthodox production and consumption economy, a new type of economy gained importance, one which is based on diffusion of know-how and technology. Based on economic and social welfare augmentation through the pillars of human capital, entrepreneurship, innovation, creation and diffusion of technology, knowledge based economy brings a breath of fresh air to the existing exogenous growth theories.

The world economy has been in a period referred to as the 'information age' with the diffusion of ICT technologies. The shift from the traditional industry that started with the Industrial Revolution during the late 18th century has changed the appearance of the economic order. Rather than the lasting Fordist production lines which aim at mass production with an automation process of workers, in the so-called information age, the rise of information-intensive industries and high technology engender a great need for competitiveness. From individuals to countries, from the private sector to the public sector, all actors acknowledged that competitiveness is the key to success, and in order to maintain sustainable growth rates and to survive in the market, one should not just adapt and adopt new technologies but should also create innovation and human capital.

Adam Smith in his 'Wealth of Nations' emphasized that the wealth and prosperity of nations depends heavily on the productive powers of the labor in addition to the capital (1776). This remarkable point later turned into the notion of innovation, which is shaped by the codified and tacit knowledge of the worker.

Referring to innovation as any kind of new combination, Schumpeter (1939) defines innovation as 'setting up a new production function' that creates disequilibrium and carries the existing economic system to a new stationary situation of equilibrium. Rather than a shift along the production function frontier, Schumpeter's definition of innovation refers to the economic notion of a shift of the production function itself (Hagedoorn, 1996).

Despite similarly large investments in research and development (R\&D) by various industrialized and semiindustrialized countries starting in the 1950s and 60s, Freeman (1995) argued that the rates of technical change and economic growth depend on efficient use of resources and innovation efficiency rather than being the first in the world with radical innovations. In addition, Freeman emphasizes that as much as technical innovation, social innovations play a significant role in economic growth and development.

Thus in the recent decade, rather than excessive R\&D spending in each and every sector, national and regional innovation systems and strategies arose which give necessary importance to the concept of Triple Helix and factor endowments of countries and regions in order to maximize their competitive advantage.

National Innovation Systems (NIS), discussed and explained by Freeman in 1987, Lundvall in 1992 and Nelson in 1993, can be briefly summarized as the relationship between the actors in the Triple Helix. These differences in the relationships affect the national innovation capacity of the countries as discussed in the literature. Freeman (1987) defines NIS as the network of institutions in the public and private sectors whose activities and interactions initiate, import, modify and diffuse new technologies, while Lunvall (1992) describes it as the elements and relationships which interact in the production, diffusion and use of new, and economically useful, knowledge. Nelson (1993) portrays as a set of institutions whose interactions determine the innovative performance of national firms.

Inaddition, Porter (1990) underlines that competition in today's world is more dynamic than in the days of classical production functions, and that nations with the economic goal of producing a high and rising standard of living for its citizens should increase their ability to maintain an efficient productivity. This efficient productivity lies on competitive advantage, which rests on continual innovation. Thus, it is crucial to compare national innovation efficiency of nations in order to implement sound policies for increasing the efficient use of scarce resources.

Since these terms have played a significant role in the sustainable economic growth and social welfare since the 2007 financial crisis, policies implemented by countries at the regional or national level to maintain growth and welfare have strategic arguments about innovation and knowledge-based economy to realize the goals set for the short term, the mid-term and the long term. In order to set these goals and implement the necessary 
policies, countries should be able to measure their input and how efficiently they turn these inputs into value added output.

Thus, the aim of this study is to measure the national innovation efficiency of 58 countries between 2007-2012 by using Data Envelopment Analysis by grouping the countries according to their gross domestic product (GDP) and gross domestic product per capita (GDP per capita) .

\section{LITERATURE REVIEW}

There is an abundance of studies on the innovation and productive efficiency of local, regional and countrybased decision making units in addition to various organizational structures such as government bodies, educational institutions, health institutions and firms. Since the focus of this study is the innovation efficiency of countries relative to each other, a literature review on measuring the innovation efficiency is presented. It is important to emphasize that in all research R\&D, expenditures and patents are assumed as the key input and output for innovation and R\&D efficiency.

Literature heavily used the the data envelopment analysis model (DEA) developed by Charnes, Cooper and Rhodes (CCR) in 1978 since it allows measuring and comparing efficiency ratios without requiring a predefined function of R\&D and knowledge ( $R \& D$ and knowledge cover multiple inputs and outputs, making it hard to place into the functions). DEA overcomes this problem by enabling each DMU's efficiency as a ratio of weighted outputs to inputs subject to the condition that the similar ratios for DMUs are between 0 and 1 (Charnes et al., 1978).

By emphasizing the difficulty of evaluating the efficiency of public institutions, Rousseau (1997) defines public institutions as the DMUs of his research and uses a constant returns to scale (CRS) and output oriented DEA model on 18 countries. He defines his input indicators as active population, R\&D expenditure and GDP. The reason for choosing active population is that the larger the active population in the economy, the greater the potential of the nation, according to Rousseau. For output indicators, he chooses the number of publications in ISI's 1993 Science Citation Index (sources) and the number of patents granted in 1993 by the European Patent Office (EPO). According to the data model, Austria, Germany, Ireland, the Netherlands, Switzerland, the UK and Canada achieve the highest efficiency in comparison with 11 other countries This study also emphasizes that spending a higher ratio of the GDP as R\&D does not bring higher efficiency ratios, since the relatively most efficient countries have different $R \& D$ expenditures ratios.

Rousseau and Rousseau (1998) analyze the same set of countries with the same set of inputs and outputs but assigning different weight to outputs and inputs. Their study, conducted for the year 1993, shows that no matter what weight is given to inputs and outputs, Switzerland is by far the most efficient and effective country among the 18 countries chosen for the study.

Nasierowski and Arcelus (2003) choose 46 countries that are listed in the World Competitiveness Report and apply a CRS input-oriented DEA model to analyze the national innovation system efficiency for the years 1993 and 1997. Japan, Taiwan and Switzerland remain the fully efficient countries in all three different models and in both years.

Based on the previous empirical work of Goto and Suzuki (1989), Adams and Griliches (2000) and Guellec and van Pottelsberghe de la Potterie (2004), Wang and Huang consider the time lag as three years and assume that the input data of 1997, 1998 and 1999 corresponds to the output data of 2000, 2001, 2002. Since the addition of inputs does not lead to immediate change in the output, time lag is introduced to the literature (Griliches, 1979; Goto and Suzuki, 1989).

Hollanders and Esser (2007) used the main dimensions of the European Innovation Scorecard to employ a CRS output oriented DEA model on 28 EU countries and Iceland and Sweden. As Wang and Huang (2007)did Hollander and Esser (2007) also emphasized the importance of time lags since the transformation of innovation inputs into innovation outputs requires time.

Another cross country analysis was conducted by Sharma and Thomas (2008) on 22 countries with gross domestic expenditure on R\&D, researchers per million population, gross domestic product (GDP) as input 
variables and patents granted to residents; all author publication counts as output variables and created four different models with different output-input combinations. The results showed that the total number of efficient nations varies significantly from one model to the other.

All these studies conducted to measure the national innovation efficiency consider certain input and output indicators such as R\&D expenditure, total number of researchers in the country in inputs, and publications, patents and high tech exports as GDP. OECD and BRICS countries are most frequently studied since the data available for those countries is more reliable and missing data is least. In addition, the missing data set creates little country bias and most of the studies mentioned in the literature review either eliminates countries assumed to be outliers or else categorize them as efficient countries.

\section{DATA AND METHODOLOGY}

The first classical DEA model developed by Charnes, Rhodes and Cooper in 1978 is also known as the constant return on scale DEA model (CRS DEA). The variable returns to scale DEA (VRS DEA) model developed by Banker, Charnes and Cooper (1984, BCC) argue that there can be increasing, constant and diminishing returns to scale at different points on the production frontier and by introducing the term 'scale efficiency' they quantify the ratio of CRS DEA to VRS DEA. The main difference between the CRS DEA and the VRS DEA is that in the CRS DEA an increase in input leaves the average productivity unchanged, where as in increasing returns to scale the same increase in the input also increases the average productivity. By contrast, in decreasing or diminishing return to scale, the same amount of increase in the input causes a decline in the average productivity.

The DEA model can also be classified under two depending on whether it is input-oriented or output-oriented. The choice of an input-oriented or output-oriented model depends on the process in the DMU and the model created to analyze. Minimizing the use of inputs to produce a given level of output defines the input-oriented method whereas maximizing the level of output given the levels of input defines the output-oriented method. This study continues with input oriented model since controlling the level of inputs rather than outputs are more effective.

The data is utilized under two different input-oriented CRS (or CCI) and VRS (or BCCI) DEA models between 2007 and 2012, the global economic crisis period. One of the aims was to determine whether innovation policies and national innovation strategies have been affected by the global crisis. The second aim was to capture the impact of the 'time lag effect' in the sample. Therefore, the second model takes into account time lag effect. Studies conducted by Wang and Huang (2007) and Hollanders and Esser (2007) indicate that the transformation of innovation inputs to innovation outputs needs time to diffuse and realize itself. Although Wang and Huang set the time lags as three years, based on the empirical work of Goto and Suzuki (1989), Adams and Griliches (2000), and Guellec and Van Pottelsberghe de la Potterie (2004), this study set the time lag as two years (Hollanders and Esser, 2007; Sharma and Thomas, 2008; Cullman et al., 2009) such that for the output data taken for the years 2007-2012, the input data gathered for the years 2005-2010 was used. As a second and third step, countries are grouped according to their GDP and GDP per capita and the innovation efficiency of the countries are measured within the groups by implementing the same models discussed above to avoid the small country bias.

Table 1 and Table 2 below shows the input and output indicators used in the model. Those indicators listed in the tables are chosen by analyzing the global indexes measuring innovation efficiency such as Global Innovation Index, Global Competitiveness Index, and European Union Innovation Scorecard. These indicators are chosen among various indicators and eliminated according to the correlation with each other. In addition to that, those are the variables that are available for 58 countries chosen for the study from 2007 to 2012. 
Table 1: Inputs of the Model

\begin{tabular}{|l|l|l|}
\hline Indicator of & Inputs & Source \\
\hline R\&D Diffusion from abroad & Net FDI Infow in billions (current US\$) & World Bank \\
\hline \multirow{2}{*}{$\begin{array}{l}\text { Ruman Resources and } \\
\text { Research Infrastructure }\end{array}$} & Expenditure on R\&D in billions (current US\$) & World Bank \\
\cline { 2 - 3 } & Total researchers per million habitants & World Bank \\
\hline \multirow{2}{*}{ ICT Infrastructure } & Internet users per 100 people & World Bank \\
\cline { 2 - 3 } & Mobile subscriptions per 100 people & World Bank \\
\hline General Infrastructure & Electricity Consumption (kWh per capita) & World Bank \\
\hline \multirow{2}{*}{ Ecological sustainability } & $\begin{array}{l}\text { GDP per unit of energy use (constant 2011 PPP \$ per kg of oil } \\
\text { equivalent) }\end{array}$ & World Bank \\
\hline
\end{tabular}

Table 2: Outputs of the Model

\begin{tabular}{|l|l|l|}
\hline Indicator of & Outputs & Source \\
\hline Knowledge Creation & Patents per million population & WIPO \\
\hline Knowledge Creation & Publications per million pop & $\begin{array}{l}\text { Scientific Journal Rankings All } \\
\text { Documents }\end{array}$ \\
\hline Knowledge Impact & $\begin{array}{l}\text { ISO } 9001 \text { certificates issued in absolute } \\
\text { numbers }\end{array}$ & $\begin{array}{l}\text { International Organization for } \\
\text { Standardization }\end{array}$ \\
\hline Knowledge Diffusion & $\begin{array}{l}\text { High technology exports in billions (current } \\
\text { US\$) }\end{array}$ & World Bank \\
\hline
\end{tabular}

\section{FINDINGS AND DISCUSSIONS}

Prior to grouping of the countries according to their GDP and GDP per capita, input oriented CRS (CCI), input oriented VRS ( $\mathrm{BCCl}$ ) and output oriented VRS (BCCO) models are conducted both in time lag and no time lag (base model) cases to see the average efficiency of the countries during the crisis and how the crisis affected the number of efficient countries.

To sum up the findings of the CCR DEA model, the input-oriented BCC and the output-oriented BCC DEA models, the average scores and the number of the efficient countries are presented for the period studied. Table 3 compares the base model and lag model averages across the years and gives a summary of the innovation efficiency of the 56 countries included in the study. It is important to emphasize that in the base model, the lowest efficiency ratios are seen right after the crisis in 2008, while in the lag model the lowest ratios are seen after 2 years, in 2009. It is also worth noting that the BCC input-oriented model presents the highest average efficiency ratios in both the base model and the lag model. 
Table 3: Average Efficiency Scores During the Global Crisis

\begin{tabular}{|l|c|c|c|c|c|c|c|c|c|c|c|c|}
\hline & \multicolumn{9}{|c|}{ Base Model } & \multicolumn{1}{c|}{ Lag Model } \\
\hline & 2007 & 2008 & 2009 & 2010 & 2011 & 2012 & 2007 & 2008 & 2009 & 2010 & 2011 & 2012 \\
\hline CCR & 0.71 & 0.69 & 0.71 & 0.72 & 0.69 & 0.71 & 0.79 & 0.77 & 0.74 & 0.75 & 0.77 & 0.78 \\
\hline BCC Input & 0.86 & 0.84 & 0.86 & 0.86 & 0.83 & 0.84 & 0.91 & 0.88 & 0.85 & 0.85 & 0.88 & 0.89 \\
\hline BCC Output & 0.77 & 0.73 & 0.77 & 0.79 & 0.75 & 0.76 & 0.87 & 0.82 & 0.78 & 0.79 & 0.84 & 0.84 \\
\hline
\end{tabular}

Table 4 below presents the number of efficient countries according to model and year. In the base model for the year 2010, the input-oriented BCC efficiency ratio is higher than the same year's output-oriented BCC average, although the number of efficient countries is lower.

Table 4: Number of Efficient Countries

\begin{tabular}{|c|c|c|c|c|c|c|c|c|c|c|c|c|}
\hline & \multicolumn{6}{|c|}{ Base Model } & \multicolumn{6}{|c|}{ Lag Model } \\
\hline & 2007 & 2008 & 2009 & 2010 & 2011 & 2012 & 2007 & 2008 & 2009 & 2010 & 2011 & 2012 \\
\hline CCR & 14 & 7 & 10 & 16 & 9 & 11 & 16 & 11 & 6 & 9 & 16 & 20 \\
\hline BCC Input & 19 & 11 & 18 & 19 & 11 & 15 & 28 & 15 & 7 & 12 & 23 & 25 \\
\hline BCC Output & 19 & 11 & 16 & 22 & 11 & 15 & 28 & 15 & 7 & 12 & 22 & 24 \\
\hline
\end{tabular}

Then as the first step, countries are grouped according to their GDP and GDP per capita and input oriented CRS and input oriented VRS models are applied both with time lag effect of 2 years and with no time lag .

Figure 1 and Figure 2 show graphical representations of GDP groups in the base and the lag model year. It gives a summary of the changes of the trends in innovation efficiency. In Figure 1, the rise of the innovation efficiency of Group 4 is seen to be substantial. On the other hand, Group 1 has a very slight change in its average ratios. In the base model, in the year 2008, all groups had a decrease in their efficiency ratios while in the lag model, the years 2009 and 2010 represent significant decreases in efficiency ratios, especially in Group 3's average efficiency.

Figure 1. Base Model Input Oriented CCR According to GDP Group

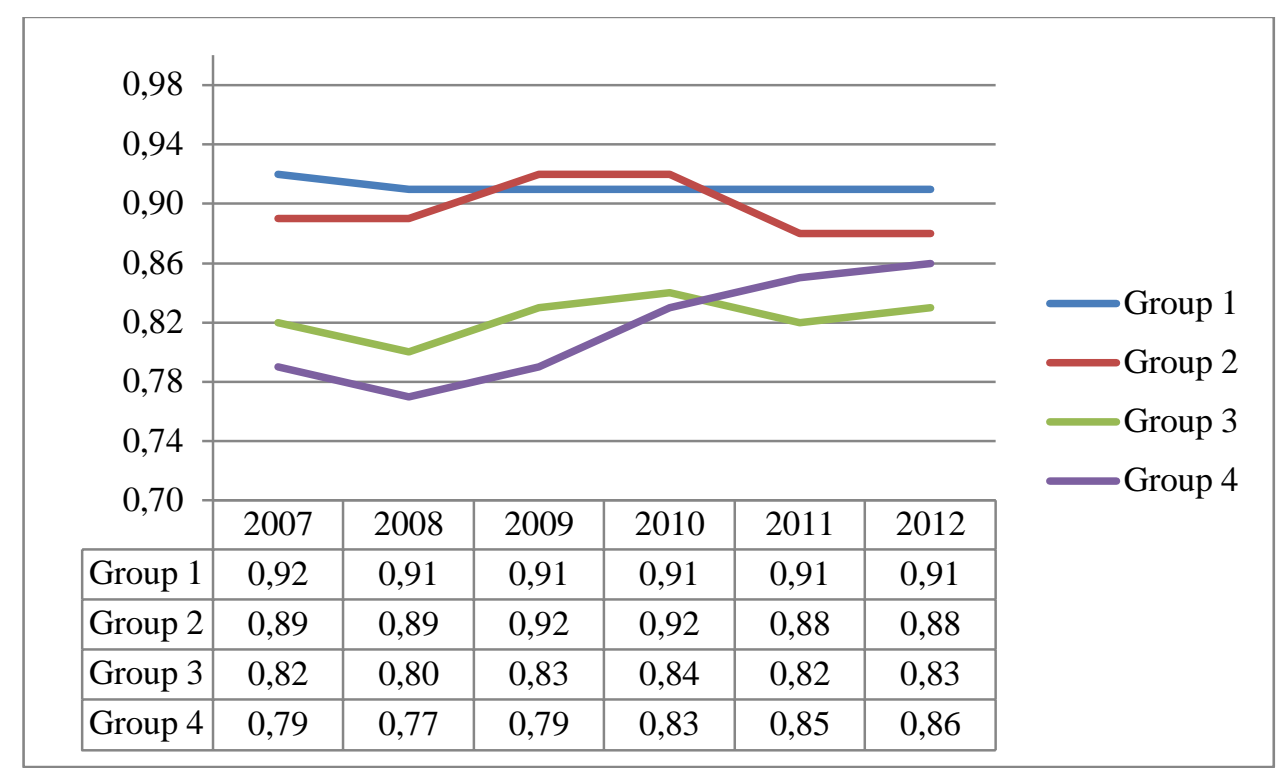


Figure 2: Lag Model Input Oriented CCR According to GDP Group

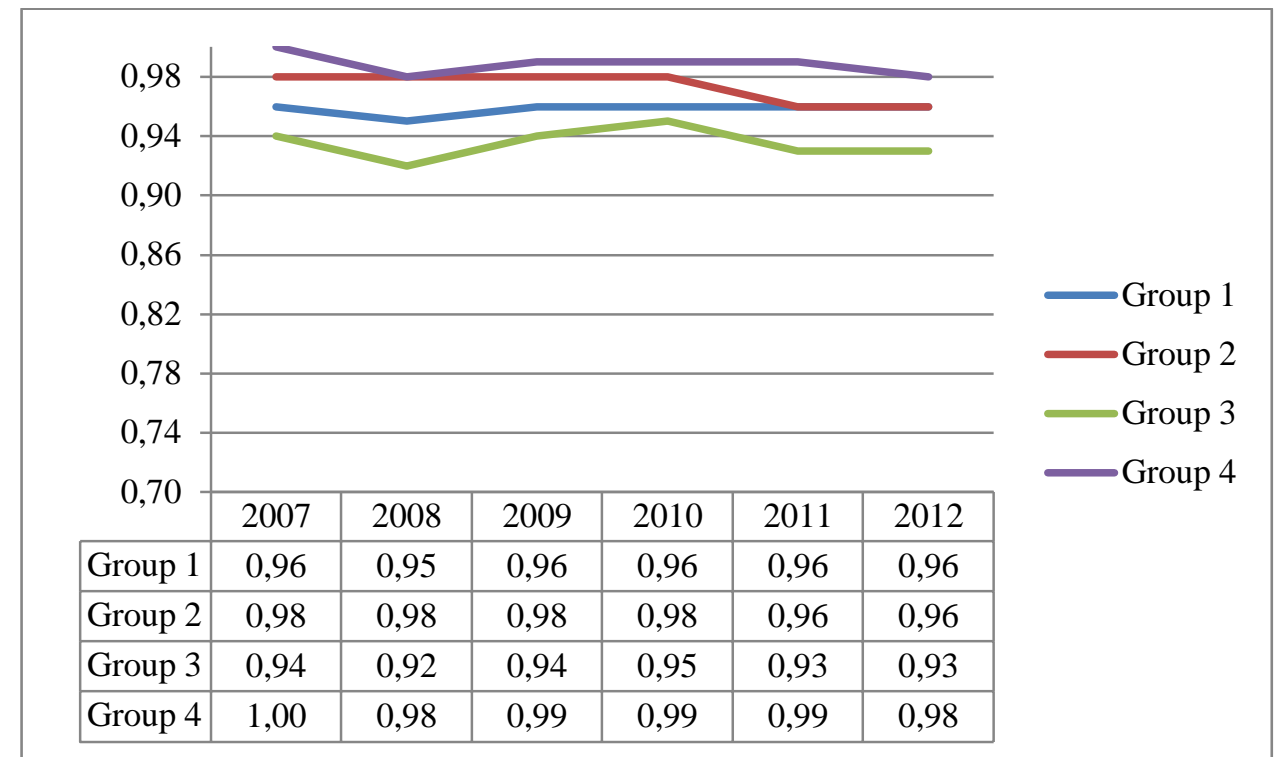

Figure 3: Base Model Input Oriented BCC According to GDP Group

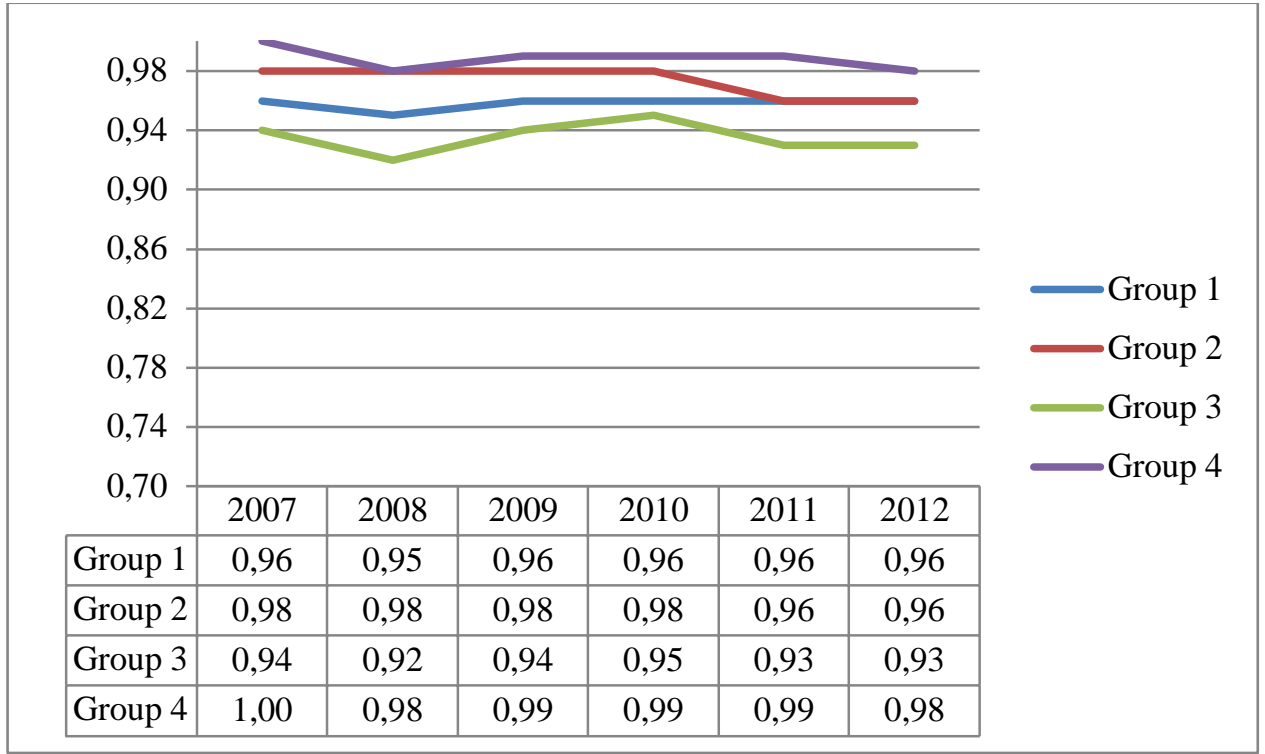

Figure 3 and Figure 4 are graphical representations of GDP groups in base and lag models by yearly base with BBC model. The BBC model represents sharper decreases than the CCR model for all Groups except Group 2 in base model year of 2008-2009. It is also important to underline that the efficiency ratio of Group 4 in the lag model is higher than any Group average, as shown in Figure 4. 
Figure 4: Lag Model Input Oriented BBC According to GDP Group

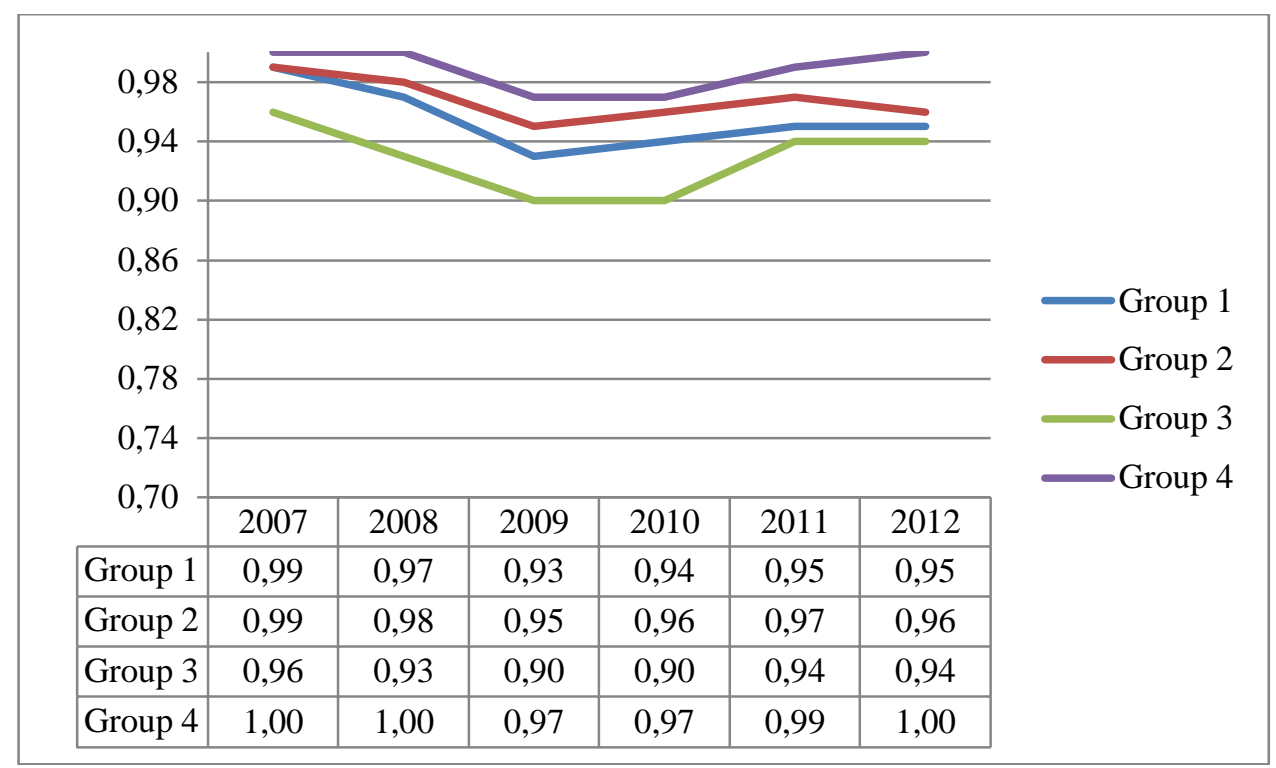

Figure 5 gives a brief visualization of efficiency averages under CCRI for the base model and the graph shows that highest GDP per capita does not lead higher efficiency although those countries are innovation-driven. This shows that scarce resources are wasted compared to Group 2 countries, which are in the transition period from efficiency-driven to innovation-driven.

Figure 5: Base Model Input Oriented CCR According to GDP per Capita Group

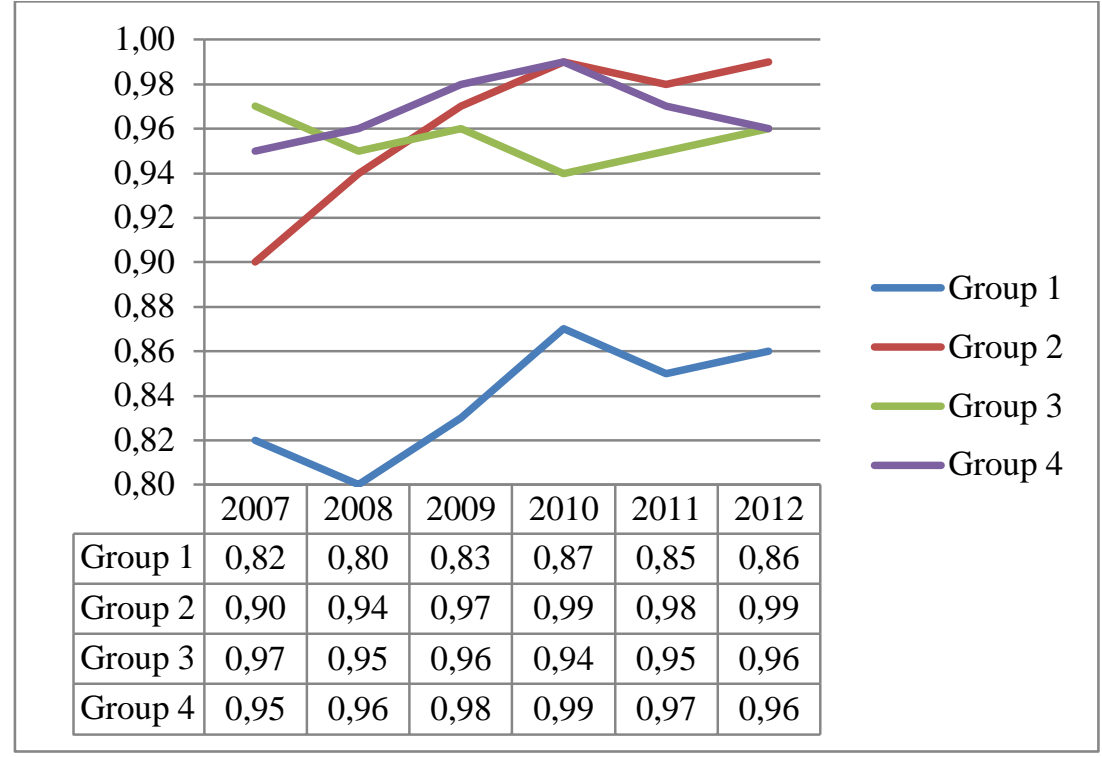


Figure 6 shows the average ratios under CRRI for the time lag period, and the decrease in the efficiency averages of Groups 1, 2 and 4 in the year 2009 is substantial. Group 3 has a sharp decrease due to the decrease in Bulgaria and China's efficiency in 2009.

Figure 6: Lag Model Input Oriented CCR According to GDP per Capita Group

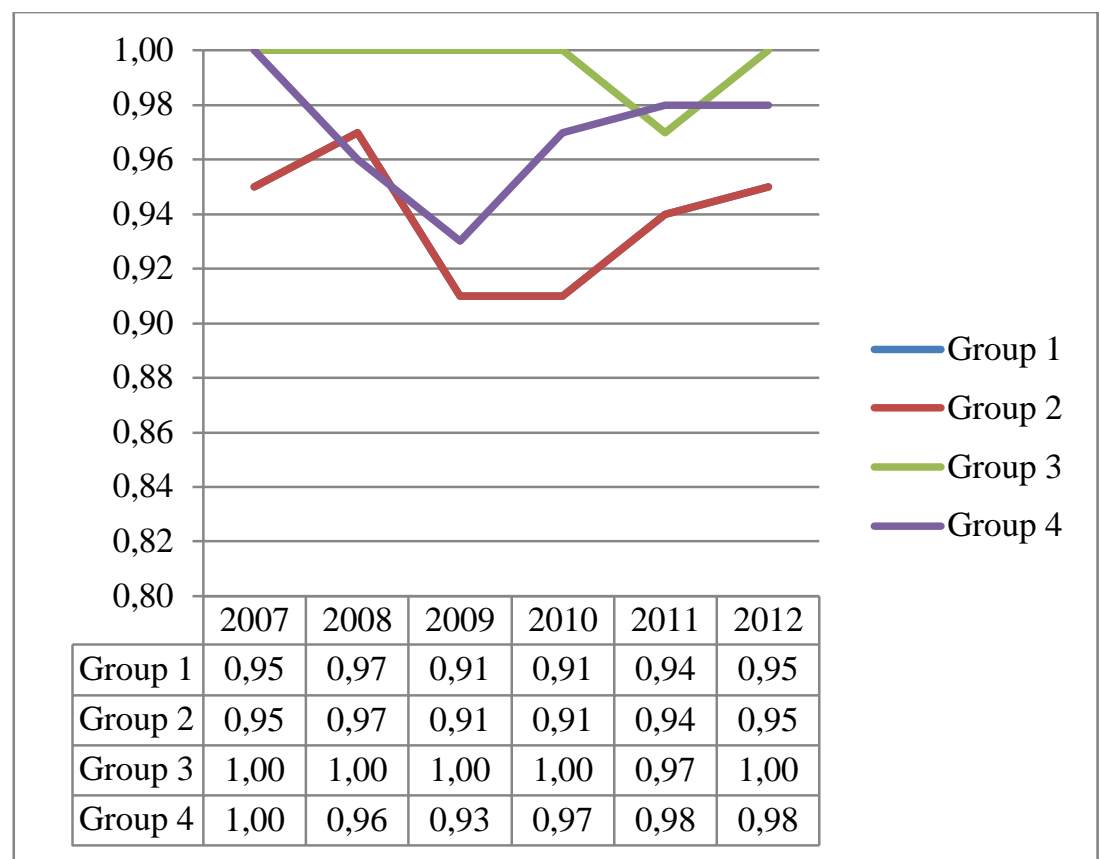

Figure 7 shows the BCCI base model under GDP per capita and it reveals that the lowest efficiency belongs to Group 1 for all years, whereas Group 4 faces a significant drop in its average due to Indonesia's and Nigeria's decreasing efficiency.

Figure 7: Base Model Input Oriented BBC According to GDP per Capita Group

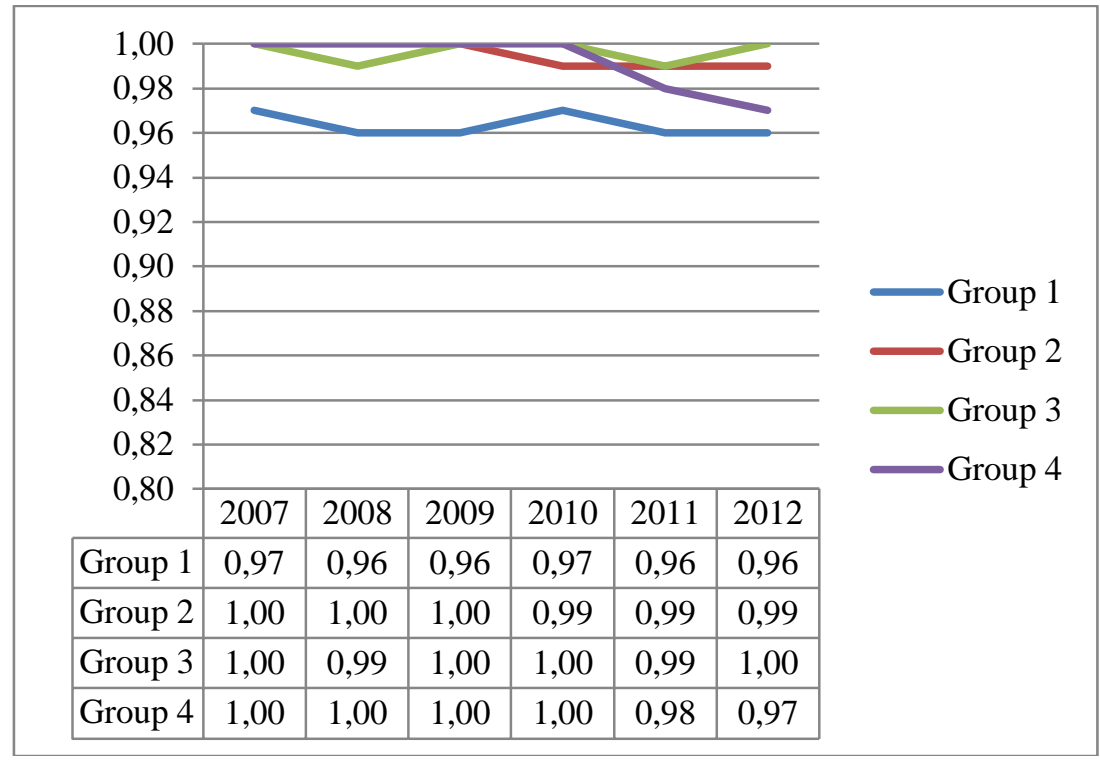


Figure 8 shows $\mathrm{BCCl}$ in the base model and indicates that Group 4 faces a significant decrease in its average during the years 2008 and 2009 due to Pakistan, the Philippines and Indonesia. Group 1, with the lowest efficiency score after 2010, faces the lowest average due to Norway and Austria's low efficiencies.

\section{Figure 8: Lag Model Input Oriented BBC According to GDP per Capita Group}

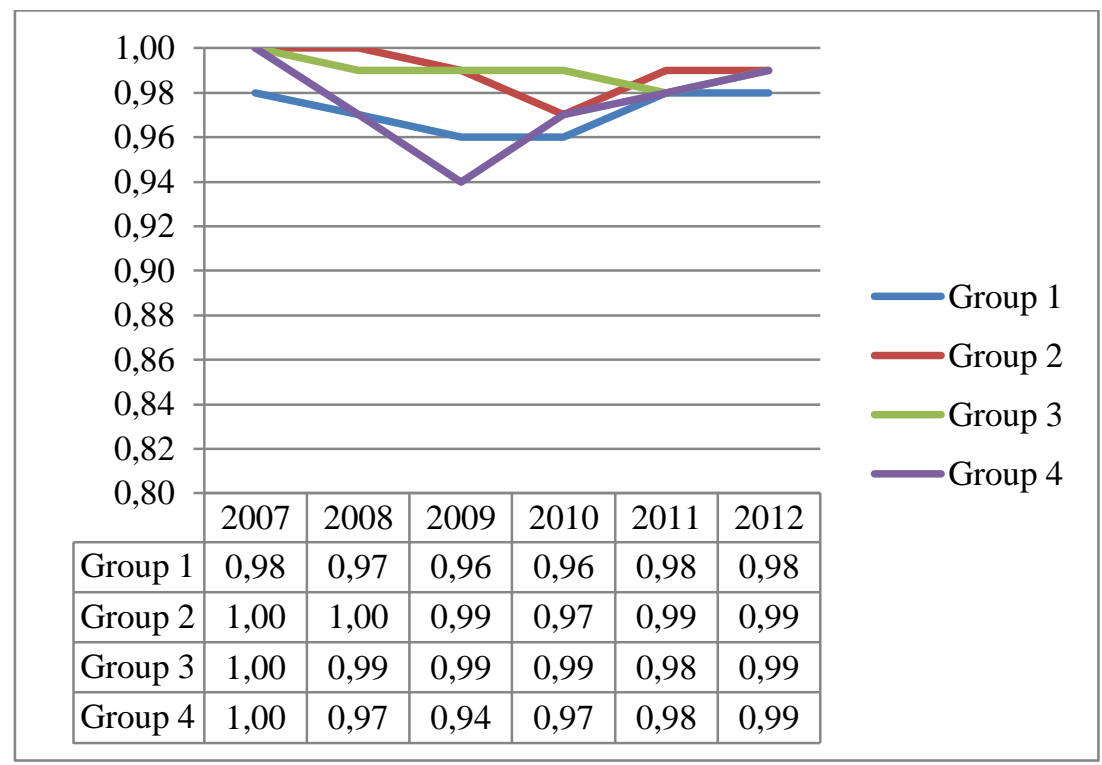

\section{CONCLUSION}

In this study countries are grouped according to two indicators, specifically, GDP and GDP per capita. After grouping the countries according to GDP, CCRI, BCCl and BCCO analyses were applied to the base model and the time lag model with 2 years of lag. In all cases, countries like Argentina, Brazil and Turkey faced the lowest efficiency ratios whereas Russia and Egypt got the lowest efficiency ratios in the CCRI and BCCO analyses.

When countries were grouped according to their GDP per capita, in the CCCl model, Australia, Belgium, Norway, Ireland, Argentina, Mexico, Bulgaria and Pakistan achieved low efficiency scores. On the other hand, in the BCCI model, all BRICS countries and Turkey faced very low efficiency in their groups.

Turkey, spending only $0.53 \%$ of its GDP for R\&D in 2002, reached almost 1\% of GDP spending in R\&D in 2013. R\&D expenditure per inhabitant rose from 46PPP US\$ in 2002 to 166 PPP US\$ in 2012, according to the Turkish Statistical Institute (TSI). GERD, HERD and especially BERD keep increasing for the last 9 years starting from 2013 with the exception of the year 2009, when the BERD faced the negative effects of the crisis after two years (TSI). Full-time employed R\&D personnel reached 105.000 in 2012, up from 29.000 in 2002. According to data gathered from Thomson Reuters, the number of academic journal articles increased to 25.018 in 2012, up from 8.975 in 2002. In addition to all these indicators, according to the Turkish Patent Institute, total patent applications done to TPI reached 11.599 in 2012, and increase of 600\% since 2002.

Although all these indicators show that Turkey increased its investments in R\&D and got positive outcomes and returns, the innovation efficiency ratio in the empirical data shows that, in comparison with other countries, Turkey still has a low innovation-efficiency ratio. This result reveals that Turkey could produce more output with the same input, or that Turkey should minimize its inputs and still produce same amount of output. For a middle-income country like Turkey, innovation and efficient use of resources are the only ways to avoid the 
middle income trap, as has been pointed out earlier, and to upgrade from the group of transition countries to the innovation-driven group.

Generating clusters and encouraging networks in the Triple Helix will definitely enhance the efficient use of resources because cluster effects and networks will minimize iteration in research and maximize knowledge diffusion. Furthermore, grant programs offered by national and international institutions and government bodies should be gathered under an umbrella organization so that every researcher or each organizational body can access and learn about ongoing research groups and projects. Transforming published articles or patents taken, into added value for the economy and the society should be a priority since research that is left behind closed doors leads neither to a multiplier effect nor to best practices that the country needs.

This study contributes to the literature in the following ways:

-By examining the years from 2007 to 2012 under two models, the base model and the 2-year lag model;

-By analyzing 56 countries and grouping them according to their GDP and GDP per capita;

For future studies, much can be done. In order to find the fundamental reasons for the low efficiency ratio in Turkey, a NUTS 2 region base study can be conducted. After the establishment of regional innovation agencies in 26 NUTS 2 regions in 2009, Turkey took a step towards concrete and permanent solutions to regional inequalities. Since each and every region's inputs differ from one another, it is extremely important to conduct regional development and innovation system plans. In addition to that, a new study is being conducted by the authors of this study focusing on a longer period of time and having a deeper analysis of the reasons behind the higher and lower efficiency performances of countries during and after the crisis ( a study focusing on the indicators and policy implementations during and after the crisis).

Taking a step further and deepening this study at the regional level will enable policymakers to measure the innovation efficiency of regions and compare various regions with high income per capita to low income per capita to set their program calls for projects in the areas predetermined by the deficiencies of innovation efficiency. Transferring resources between sectors and organizing the strategic priorities of the region accordingly will definitely enhance the knowledge and the innovation lead by the region and strengthen the regional welfare.

\section{REFERENCES}

Charnes, A., Cooper, W.W. \& Rhodes, E. (1978). Measuring the Efficiency of Decision Making Units. European Journal of Operational Research, 2, 429-444.

European Innovation Union Scorecard. (2014). Retrieved from: http://ec.europa.eu/enterprise/policies/innovation/policy/innovationscoreboard/index_en.htm

Freeman, C. (1995). The National System of Innovation in Historical Perspective. Cambridge Journal of Economics, $19,5-24$.

Global Competitiveness Index. (2013). Retrieved from: http://www.weforum.org/issues/global-competitiveness

Global Innovation Index. (2013). Retrieved from: http://www.globalinnovationindex.org/content.aspx?page=GII-Home

Goto, A. \& Suzuki, K. (1989). R\&D Capital, Rate of Return on R\&D Investment and Spillover of R\&D in Japanese Manufacturing Industries. Review of Economics and Statistics, 71, 555-564.

Griliches, Z. (1998). Introduction to R\&D and Productivity: The Econometric Evidence. In Griliches, Zvi (Ed.), R\&D and Productivity: The Econometric Evidence (pp. 1-45). University of Chicago Press.

Guellec, D. \& Van Pottelsberghe Potterie, B. (2004) . From R\&D to Productivity Growth: Do the Institutional Settings and the Source of Funds of R\&D Matter? Oxford Bulletin of Economics and Statistics. 66 (3), 353-378.

Hagedoorn, J. (1996). Innovation and Entrepreneurship: Schumpeter Revisisted. Industrial and Corporate Change. 5(3) , 883-896.

Hollanders, H. \& Esser, F. (2007). Measuring Innovation Efficiency. INNO-Metrics Thematic Paper. Retrieved from: http://www.pedz.unimannheim.de/daten/edz-h/gdb/07/eis_2007_Innovation_efficiency.pdf 
Lundvall ,Bengt-Åke (2004). National Innovation Systems- Analytical Concept and Development. Retrieved from: http://www.druid.dk/conferences/Summer2005/Papers/Lundvall.pdf

Nasierowski, W. \& Arcelus, F.J. F.J. (2003) On the Efficiency of National Innovation Systems. Socio-Economic Planning Sciences, 37, 215234.

Nelson, R. (1993). National Innovation Systems: A Comparative Analysis. New York: Oxford University Press

Porter, M. (1990). The Competitive Advantage of Nations. Macmillan:Basingstoke.

Rousseau, S. \& Rousseau, R. (1997). DEA as a Tool for Construction Scientometric Indicators. Scientometrics, 40(1), 45-56.

Schumpeter, Joseph A. (1939). Business cycles: a theoretical, historical, and statistical analysis of the capitalist process. Martino Publications.

Sharma, S. \& Thomas, V.J. (2008). Inter-country R\&D Efficiency Analysis:

An Application of Data Envelopment Analysis. Scientometrics, 76(3), 483-501.

Smith, A. (1776). An Inquiry into the Nature and Causes of the Wealth of Nations. London: W. Strahan.

Wang, E. \& Huang, W. (2007). Relative Efficiency of R\&D Activities: A Cross-Country Study Accounting for Environmental Factors in the DEA Approach. Research Policy, 36, 260-273.

\section{Appendix 1.}

Countries that are used in the study are Argentina, Australia, Austria, Belgium, Brazil, Bulgaria, Canada, Chile, China, Columbia, Czech Republic, Denmark, Egypt, Estonia, Finland, France, Germany, Greece, Hong Kong, Hungary, Iceland, India, Indonesia, Ireland, Israel, Italy, Japan, Latvia, Lithuania, Luxembourg, Malaysia, Mexico, Netherlands, New Zealand, Nigeria, Norway, Pakistan, Philippines, Poland, Portugal, Romania, Russian Federation, Singapore, Slovak Republic, Slovenia, South Korea, South Africa, Spain, Sweden, Switzerland, Thailand, Turkey, Ukraine, United Kingdom, United States.

GDP Groups

Four groups were formed according to the countries' economic capacity:

Group 1: GDP more than 1.5 trillion USD (top 10 countries in GDP ranking: United States, China, Japan, Germany, France, the United Kingdom, Brazil, Italy, India, Canada)

Group 2: GDP between 500 billion USD and 1.5 trillion USD (countries ranking between 10 and 19 in GDP ranking: the Russian Federation, Spain, Australia, Mexico, South Korea, the Netherlands, Turkey, Indonesia, Switzerland)

Group 3: GDP between 100 and 499 billion USD (Belgium, Poland, Sweden, Norway, Austria, Argentina, Nigeria, South Africa, Thailand, Denmark, Greece, Columbia, Malaysia, Finland, Singapore, Israel, Portugal, Hong Kong, Egypt, Chile, Ireland, Philippines, Czech Republic, Pakistan, Romania, New Zealand, Ukraine, Hungary)

Group 4: GDP less than 100 billion USD (Slovak Republic, Luxembourg, Bulgaria, Slovenia, Lithuania, Latvia, Estonia, Iceland)

GDP Per Capita $(\mathrm{GCl}, 2013)$

Countries in the sample set are classified as follows:

Group 1: Innovation-driven countries (Luxembourg, Norway, Switzerland, Denmark, Australia, Sweden, the United States, the Netherlands, Canada, Ireland, Singapore, Austria, Finland, Belgium, Japan, Germany, Iceland, France, the United Kingdom, Italy, New Zealand, Hong Kong, Israel, Spain, Greece, Slovenia, Portugal, South Korea, Czech Republic)

Group 2: Countries in transition from efficiency-driven to innovation-driven stage (Slovak Republic, Estonia, Hungary, Chile, Poland, Lithuania, Latvia, Brazil, the Russian Federation, Turkey, Argentina)

Group 3: Efficiency-driven countries (Mexico, Malaysia, Romania, South Africa, Bulgaria, Columbia, Thailand, China)

Group 4: Countries in transition from factor-driven to efficiency-driven stage (Ukraine, Indonesia, Egypt, Nigeria, the Philippines) Factordriven countries (India, Vietnam, Pakistan)

Since there are only three countries in the factor-driven country group, these are combined with countries in transition from factor-driven to efficiency-driven stage. 